\title{
Sensory Evaluation of Selected Persian Walnut Cultivars
}

\author{
Chuck A. Ingels ${ }^{1}$, Gale H. McGranahan, and Ann C. Noble ${ }^{2}$ \\ Department of Pomology, University of California, Davis, CA 95616
}

Additional index words. English walnut, flavor, Juglans regia, nut flavor, taste panel

\begin{abstract}
To determine if flavor differences could be detected among several Persian walnut (Juglans regia L.) cultivars, difference tests with eight cultivars were conducted using the duo-trio method. No differences were found when 'Hartley' was compared to 'Vina', 'Scharsch Franquette', and 'Mayette'. However, 'Chandler', 'Chico', 'Howard', and 'Sunland' were significantly different, and paired comparisons were then used to test these cultivars against 'Hartley' in terms of several flavor characteristics. No differences in astringency and "walnut flavor" were detected; however, 'Chandler' was judged to be sweeter than 'Hartley', which was sweeter than 'Howard'. 'Chico' was found to be the firmest cultivar.
\end{abstract}

Walnut breeding programs have typically focused on commercially important nut and tree characteristics, such as percent kernel, time of leafing and flowering, and bearing habit (Chariot et al., 1988; Forde, 1975), while sensory evaluation has not been vigorously studied. Brief statements, such as "flavor good" and "kernel sweet", are often used to describe nut flavor within lengthy cultivar descriptions (Brooks and Olmo, 1972). For instance, 'Hartley' was noted as having "a mild, fairly sweet flavor" (Serr and Forde, 1956). In the walnut breeding program at the Univ. of California, Davis, nut flavor has not been used as a criterion for selecting cultivars, although until 1977, flavor was noted as "good", "fair", or "poor" for nuts of all cultivars and seedlings evaluated (Forde, 1975). Most of the cultivars evaluated were given a rating of good, but 'Franquette', 'Scharsch Franquette', and 'Pioneer' frequently received fair ratings. The

Received for publication 17 June 1989. This work was partially supported by USDA/ARS Specific Cooperative Agreement no. 58-91H2-8-131. We thank Bill Stuke for providing the walnuts used in this study. The cost of publishing this paper was defrayed in part by the payment of page charges. Under postal regulations, this paper therefore must be hereby marked advertisement solely to indicate this fact.

${ }^{1}$ Postgraduate Researcher, Sustainable Agriculture Research and Education Program.

${ }^{2}$ Dept. of Viticulture and Enology. rating of poor was very rarely used.

No previous sensory evaluation of walnuts to determine genotypic differences has been reported. The objectives in this experiment were, therefore, 1) to determine if differences between selected walnut cultivars can be detected by members of a taste panel and 2) where differences exist, to have the panel members compare these cultivars on the basis of several characteristics.

Preparation of nuts. Nuts from walnut cultivars used in the experiment were harvested in Sept. and Oct. 1988, at $\approx 80 \%$ hull dehiscence, from healthy commercial orchards in the Gridley/Live Oak area of California. The nuts were immediately dried and stored at room temperature for $\approx 1$ to 3 weeks, then transferred to UC Davis, and stored in plastic bags at 0C. Moisture content was calculated by drying $100 \mathrm{~g}$ of kernels at $70 \mathrm{C}$ in a vacuum oven for $36 \mathrm{hr}$ and then reweighing. Kernel moisture content was found to be variable among cultivars and most cultivars well exceeded the optimum range of $3.2 \%$ to $3.8 \%$ (R.E. Gunnerson, personal communication). The whole nuts were therefore redried at $43 \mathrm{C}$ for $3-6 \mathrm{hr}$, cooled at room temperature, and then refrigerated in plastic bags for several days to equalize nut moisture content. The nuts were then retested; the moisture content of all the cultivars was between $3.0 \%$ and $3.4 \%$. Northern California black walnuts (J. hindsii), used in the first training session, were dried and stored in the same manner, but were not tested for moisture content. Nuts of each cultivar were cracked the day before they were to be tested, and the kernels were broken into pieces about one-sixth the size of a kernel-half. The kernels were then stored overnight in a plastic bag at $2 \mathrm{C}$.

Sensory evaluation. Twenty-one people associated with the Pomology Dept., UC Davis, were selected as judges based on motivation and availability. The panelists were advised to chew several kernel pieces, expectorate, and rinse with water between samples. However, due to individual preferences and the small number of nuts being sampled, they were given the choice to swallow or expectorate the nuts and to rinse two times after each sample or only after each trio of samples. In either case, they were told to use the same technique for the entire experiment. All evaluations were carried out in individual booths under red light at 22C.

In the initial difference testing, 'Hartley' was compared to seven other cultivars using the duo-trio method (Institute of Food Technologists, 1981). Each day, one cultivar was tested against 'Hartley' in four replications. One bowl of 'Hartley' kernels (coded as "reference") was placed on each panel member's tray along with four pairs of portion cups (coded with random three-digit numbers) that contained $\approx 6-8 \mathrm{~g}$ of kernels. In each pair, 'Hartley' kernels and kernels of the other test cultivar were presented in a random order. Panel members were asked to indicate which sample in each pair was identical to the reference sample. The first day of testing was used as a training session, in which black walnuts were tested against

Table 1. Results of difference testing of 'Hartley' vs. seven other Persian walnut cultivars and black walnut used in training session.

\begin{tabular}{lc}
\hline \hline $\begin{array}{l}\text { Cultivar compared } \\
\text { to Hartley }\end{array}$ & $\begin{array}{c}\text { No. correct } \\
\text { responses }\end{array}$ \\
\hline$J$. hindsii & $75^{* * *}$ \\
Chico & $64^{* * *}$ \\
Sunland & $64^{* * *}$ \\
Howard & $60^{* * *}$ \\
Chandler & $59^{* * *}$ \\
Vina & $50^{\text {Ns }}$ \\
Scharsch Franquette & $49^{\text {Ns }}$ \\
Mayette & $48^{\text {NS }}$ \\
\hline
\end{tabular}

${ }_{n}=21$ judges $\times$ four reps $=84$ responses. NS,***Nonsignificant or significant $P=0.001$, respectively. 
Table 2. Results of paired comparisons of four other Persian walnut cultivars to 'Hartley' for four characteristics.

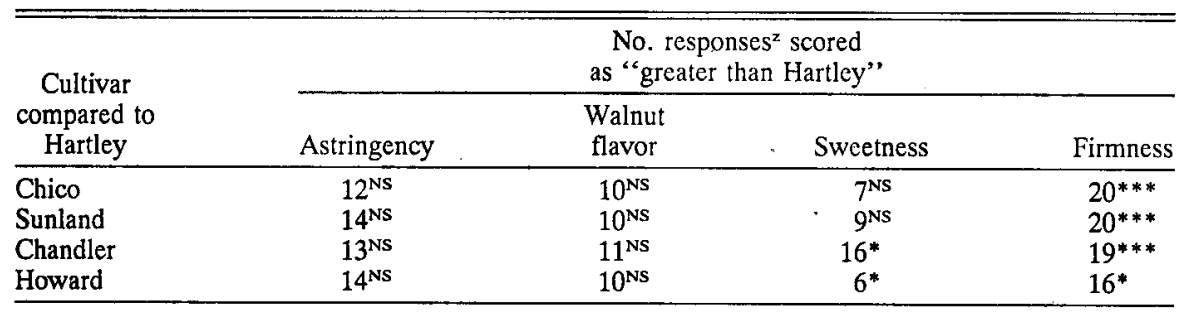

${ }^{n} n=11$ judges $\times$ two reps $=22$ responses.

Ns,****Nonsignificant or significant at $P=0.05$ or 0.001 , respectively.

Table 3. Results of paired comparisons for firmness and sweetness of Persian walnut cultivars.

\begin{tabular}{lcc}
\hline \hline $\begin{array}{c}\text { Cultivars } \\
\text { compared }\end{array}$ & $\begin{array}{c}\text { No. responses } \\
\text { (firmer) }\end{array}$ & $\begin{array}{c}\text { No. responses } \\
\text { (sweeter) }\end{array}$ \\
\hline Howard/Chico & $2 / 20^{* * *}$ & $13 / 9^{\mathrm{Ns}}$ \\
Chandler/Chico & $5 / 17^{* *}$ & $13 / 9^{\mathrm{Ns}}$ \\
Sunland/Chico & $5 / 17^{* *}$ & $12 / 10^{\mathrm{Ns}}$ \\
Howard/Sunland & $8 / 14^{\mathrm{Ns}}$ & $9 / 13^{\mathrm{Ns}}$ \\
Chandler/Sunland & $9 / 13^{\mathrm{NS}}$ & $157^{\mathrm{Ns}}$ \\
Howard/Chandler & $9 / 13^{\mathrm{NS}}$ & $3 / 19^{* * *}$ \\
\hline
\end{tabular}

$z_{n}=11$ judges $\times$ two reps $=22$ responses.

NS,**,***Nonsignificant or significant at $P=0.01$ or 0.001 , respectively.

'Hartley' to assure obvious differences. Formal testing began on day 2 of the experiment and continued through day 8; the last day was used for makeups.

Pair tests were conducted during the 3rd week to compare cultivars on the basis of firmness, astringency, sweetness, and overall walnut flavor. All testing was performed under the same conditions as those used for difference testing. Eleven panelists were selected to participate on the basis of availability and sensitivity demonstrated in the difference testing. Training consisted of 1 day during which panel members were presented with mildly sweet (5 g sucrose/liter) and astringent $(50 \mathrm{mg}$ aluminum sulfate/liter) aqueous reference solutions. In separate paired tests, in which the above solutions were compared to water, all judges correctly identified the sweet and astringent solutions. Judges were also asked to sample walnut pellicle material to taste astringency. No training was performed for firmness and "walnut flavor". 'Hartley' was then compared to 'Chandler', 'Chico', 'Howard', and 'Sunland' walnuts in paired comparisons in duplicate (eight pairs per session). Judges were asked to identify the firmer and more astringent sample in each pair one day, and the sample that was sweeter and had greater overall walnut flavor the second day. The four cultivars were then compared to each other in duplicate on the basis of firmness and sweetness, with one replication performed per day (six pairs per session).

Duo-trio and pair test results were interpreted from a table constructed from binomial probability, where $P=0.5$, one-tailed and two-tailed, respectively (Roessler et al., 1978).

The results of the difference tests are summarized in Table 1. In the training session, black walnut was highly significantly different from 'Hartley' $(P=0.001)$. Of the seven $J$ regia cultivars tested against 'Hartley', only 'Chico', 'Sunland', 'Howard', and 'Chandler' differed significantly $(P=0.001$ level).

Pair testing was performed to characterize how these four cultivars differed from 'Hartley' and from each other. No differences in astringency or overall walnut flavor were detected between 'Hartley' and the four other cultivars (Table 2). However, 'Chandler' was found to be sweeter than 'Hartley' $(P=0.05)$ and 'Hartley' was sweeter than 'Howard' $(P$ $=0.05)$. All four of the cultivars tested were firmer than 'Hartley'. The four cultivars were then tested among themselves in terms of firmness and sweetness (Table 3). 'Chico' kernels were firmer than the other three cultivars, which did not differ among themselves. Only one significant difference in sweetness was found: 'Chandler' was significantly sweeter than 'Howard' $(P=$ 0.001).

In this study, the cultivar Hartley was shown to be significantly different in sensory properties from 'Chandler', 'Chico', 'Howard', and 'Sunland', while not differing from 'Vina', 'Scharsch Franquette', and 'Mayette'. In pair tests, all four cultivars were found to be firmer than 'Hartley', while two differed in sweetness. None of the four cultivars differed from 'Hartley' in astringency or in walnut flavor.

The majority of walnuts are used as ingredients in food products, such as baked goods, in which case the difference in firmness or sweetness of these cultivars may not be important. In walnuts sold for fresh consumption, however, consumer preference for firmer or sweeter nuts would have to be assessed before either characteristic is used as a criterion for influencing cultivar selection. Although intensity of walnut flavor did not differ for these cultivars, it may be an important characteristic to assess in new cultivars. Based on these tests, it is also suggested that in evaluating new cultivars or germplasm, initial sensory evaluation should screen for occurrence of strong, atypical flavors, rather than for subtle differences such as those found here.

\section{Literature Cited}

Brooks, R.M. and H.P. Olmo. 1972. Register of new fruit $\&$ nut varieties, 2 nd ed. Univ. of California Press, Berkeley.

Chariot, G., E. Germain, and J.-P. Prunet. 1988. Le noyer. Centre Technique Interprofessionel des Fruits et Legumes, Paris.

Institute of Food Technologists. 1981. Sensory evaluation guide for testing food and beverage products. Sensory Evaluation Div., Inst. Food Technologists. Food Technol. 35(11):50-59.

Forde, H.I. 1975. Walnuts, p. 439-455. In: J. Janick and J.N. Moore (eds.). Advances in fruit breeding. Purdue Univ. Press, West Lafayette, Ind.

Roessler, E.B., R.M. Pangborn, J.L. Sidel, and H. Stone. 1978. Expanded statistical tables for estimating significance in paired-preference, pairdifference, duo-trio and triangle tests. J. Food Sci. 43:940-943.

Serr, E.F. and H.I. Forde. 1956. Walnut breeding. Proc. Amer. Soc. Hort. Sci. 68:184-194. 